\title{
Physiological Characteristics of the Mycobacterium tuberculosis-M. bovis Group of Organisms with Particular Reference to Heterogeneity within M. bovis
}

\author{
By P. A. BARROW† \\ Department of Microbiology, London School of Hygiene and Tropical Medicine, Keppel Street, \\ London WCIE $7 H T, U K$
}

( Received 22 July 1985)

By examining the abilities of mycobacterial strains to remove amino acids from solution, differences were found between Mycobacterium tuberculosis and other closely related taxa. Heterogeneity was observed in most taxa. Strains of $M$. bovis were examined in greater detail. By using the amino acid typing method in combination with tests routinely used for differentiating mycobacterial species, and SDS-polyacrylamide gel electrophoresis of whole cell soluble proteins, a great degree of heterogeneity was observed in this taxon.

\section{INTRODUCTION}

There has been much interest recently in the taxonomy of the Mycobacterium tuberculosis $-M$. bovis group of organisms. This has centred on the realization that the species $M$. tuberculosis, $M$. bovis, $M$. africanum and $M$. microti have more in common with each other than they do with other mycobacteria and should belong to one species under one name, $M$. tuberculosis (Grange, 1982). The organisms in this group are difficult to study, making the epidemiological study of infections in man and animals caused by them difficult and time consuming. Intra-specific differences have been detected which can be correlated with the ethnic origin of the hosts from which the strains were isolated (Collins et al., 1982). Bacteriophage typing has been of limited use in studying $M$. tuberculosis infection since few sub-specific divisions occur (Bates \& Mitchison, 1969), and it cannot be used for $M$. bovis since all strains appear to belong to one phage type. Pyrolysis mass spectrometry has been used to demonstrate a degree of heterogeneity among strains but this technique has not yet been applied to epidemiological problems (Wieten et al., 1981). A typing system based on the ability of strains to remove, by utilization or breakdown, different amino acids from aqueous solution was developed by Grange (1976) for the $M$. avium group. This was applied by Barrow (1981) in a study of the spread of $M$. bovis infection from a wild animal reservoir to cattle in south west England. The degree of heterogeneity found in this preliminary investigation merited a study of closely related species using this technique. The present study describes the application of this system to taxa within the $M$. tuberculosis- $M$. bovis group and demonstrates heterogeneity within $M$. bovis by other methods.

\section{METHODS}

Bacteria. All strains were maintained at $-70^{\circ} \mathrm{C}$ as a suspension in Middlebrook $7 \mathrm{H} 11$ broth (Difco) containing $50 \%(v / v)$ glycerol. They were obtained from Dr T. W. A. Little, Central Veterinary Laboratory, Weybridge; Mr J. Gallagher, Veterinary Investigation Centre, Gloucester; Dr P. A. Jenkins, Mycobacterium Reference Laboratory, Cardiff; or from Drs J. Grant and M. T. Elghul, London School of Hygiene and Tropical Medicine.

+ Present address: Houghton Poultry Research Station, Houghton, Huntingdon, Cambridgeshire PE17 2DA, UK. 
Identification procedures. The range of tests used was that described by Barrow \& Gallagher (1981). Amino acid typing procedure. This was the method of Grange (1976) as applied by Barrow (1981).

$S D S-P A G E$. The procedure for preparation of whole-cell protein extracts, the standardization of their protein concentrations and their analysis by SDS-PAGE was as described by Kersters \& De Ley (1975), but with the modification that slab gels were used and staining was done with Coomassie Brilliant Blue.

\section{RESULTS}

Amino acid utilization by the $M$. tuberculosis-M. bovis group of organisms

Considerable heterogeneity was observed in the patterns of amino acid removal among the strains tested (Table 1). The three strains of $M$. tuberculosis did not remove from solution any of the amino acids studied. One of the strains was retested; the result was identical. Several strains of $M$. bovis were studied; two 'African' strains and six 'classical' strains from man, and eight 'classical' strains from animals, four from cattle and four from badgers. A minority of these strains were completely non-reactive while others showed removal of glutamic acid, histidine or serine or combinations of these three with additional amino acids. The two BCG strains produced patterns of reaction very similar to each other, the only differences being with tyrosine and valine. Neither the $M$. microti nor the relatively closely related $M$. xenopi produced patterns of removal identical to any of the other types studied.

Apart from $M$. tuberculosis no patterns of amino acid removal appeared to be species characteristic.

Heterogeneity in $M$. bovis demonstrated by other methods

Thirty-six strains of $\boldsymbol{M}$. bovis were examined by standard identification procedures (see Methods). Five of the strains had been isolated from cattle and stored in a culture collection at

Table 1. Patterns of amino acid removal among the mycobacterial strains studied

\begin{tabular}{|c|c|c|c|c|c|c|c|c|c|c|c|c|c|c|}
\hline & & & & & & & & hova & & & & & & \\
\hline Strain & & 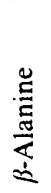 & 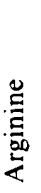 & 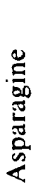 & 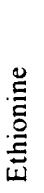 & 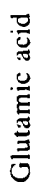 & $\frac{\mathscr{\Xi}}{\stackrel{\Xi}{\Delta}}$ & 营 & $\frac{\mathscr{5}}{3}$ & 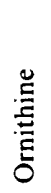 & 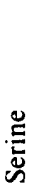 & 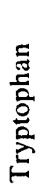 & 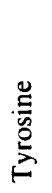 & $\underset{⿱ 乛}{\stackrel{\Xi}{\Xi}}$ \\
\hline M. tuberculosis & 1 & - & - & - & - & - & - & - & - & - & - & - & - & - \\
\hline & 2 & - & - & - & - & - & - & - & - & - & - & - & - & - \\
\hline & 3 & - & - & - & - & - & - & - & - & - & - & - & - & - \\
\hline M. bovis (African) & 1 & - & - & - & - & - & - & - & - & - & - & - & - & - \\
\hline & 2 & + & - & + & - & + & + & - & - & - & + & + & + & + \\
\hline M. bovis (human) & 1 & - & - & - & - & - & - & - & - & - & - & - & - & - \\
\hline & 2 & - & \pm & - & - & - & - & - & - & - & - & - & - & - \\
\hline & 3 & - & + & - & - & + & - & - & - & - & + & - & - & - \\
\hline & 4 & - & - & - & - & + & - & \pm & - & - & \pm & - & + & - \\
\hline & 5 & \pm & - & \pm & - & + & + & - & - & - & \pm & - & \pm & + \\
\hline & 6 & + & + & + & - & + & + & - & + & - & + & + & + & + \\
\hline M. bovis (cattle) & 1 & - & - & - & - & - & - & - & - & - & - & - & - & - \\
\hline & 2 & - & - & - & - & + & - & + & - & - & + & - & - & - \\
\hline & 3 & - & - & - & - & + & - & - & - & - & + & - & & + \\
\hline & 4 & - & - & - & - & + & - & + & - & - & - & - & - & + \\
\hline M. bovis (badger) & 1 & - & - & - & - & - & - & - & - & - & - & - & - & - \\
\hline & 2 & - & + & - & - & - & - & - & - & - & - & - & - & + \\
\hline & 3 & - & - & - & - & - & - & + & - & - & + & - & - & + \\
\hline & 4 & - & + & - & - & + & - & - & - & - & + & - & - & - \\
\hline M. bovis $\mathrm{BCG}$ & 1 & - & - & - & - & \pm & - & \pm & - & - & + & - & + & - \\
\hline & 2 & - & - & - & - & \pm & - & \pm & - & - & \pm & - & - & + \\
\hline M. microti & 1 & - & - & - & - & + & - & - & - & - & - & - & - & + \\
\hline & 2 & - & + & + & - & + & + & \pm & - & - & + & - & + & - \\
\hline M. xenopi & 1 & - & - & - & - & - & - & + & - & - & - & - & - & - \\
\hline & 2 & + & + & - & - & + & - & - & - & - & - & + & - & + \\
\hline
\end{tabular}




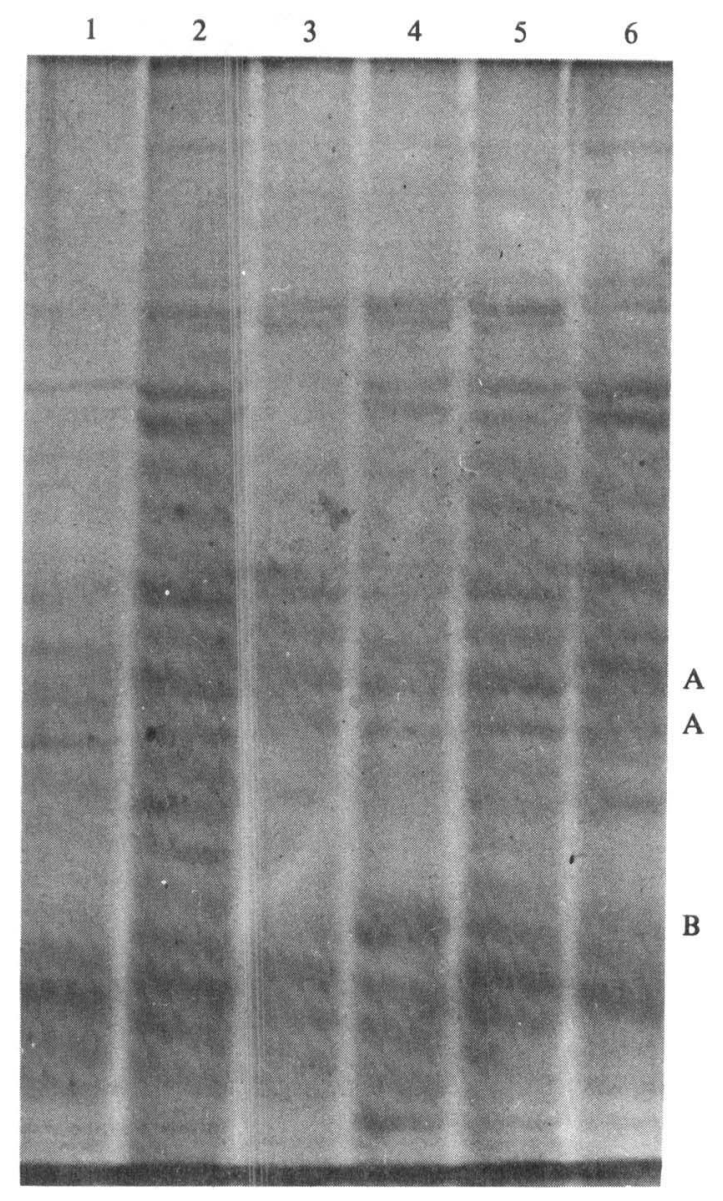

Fig. 1. SDS-PAGE of six strains of $M$. bovis isolated from badgers showing (A) some protein bands present in all strains and (B) a smaller $M_{\mathrm{r}}$ protein present in large amounts in strain 4 only.

the London School of Hygiene and Tropical Medicine for several years, and 31 strains had been recently isolated in the south west of England, 12 of them from cattle and 19 from badgers. The badger and culture collection strains, together with seven of the recently isolated cattle strains, were identical in their cultural and biochemical characteristics, typical of $M$. bovis. They grew as short to medium length rods and formed dysgonic colonies; growth was slow (4 weeks for the appearance of colonies on agar). They were positive for: growth at $37^{\circ} \mathrm{C}$ and (weakly) at $42^{\circ} \mathrm{C}$; production of arylsulphatase ( 2 weeks), urease, peroxidase and catalase; and resistance to pyrazinamide $\left(25 \mu \mathrm{g} \mathrm{m}^{-1}, \mathrm{pH} \mathrm{5.5)}\right.$. They were negative for: production of pigments in the light and the dark; growth at $25^{\circ} \mathrm{C}$ and $45^{\circ} \mathrm{C}$; hydrolysis of Tween 80 ; production of niacin, nitrate reductase and catalase resistant to heating at $68^{\circ} \mathrm{C}$; stimulation by glycerol; and resistance to potassium tellurite and thiophene-2 carboxylic acid hydrazide $\left(10 \mu \mathrm{g} \mathrm{ml}^{-1}\right)$. Five of the recently isolated cattle strains differed from the above pattern in that they were negative for the production of arylsulphatase.

Preparations of soluble, whole-cell proteins from several of the strains isolated from badgers were examined by SDS-PAGE (Fig. 1). A considerable degree of heterogeneity was observed. While some proteins, such as A, appeared to be identical in all six strains, others, such as B, appeared to be limited to individual strains. Other differences could be observed between the strains. 


\section{DISCUSSION}

Members of the $M$. tuberculosis $-M$. bovis group have more in common with each other than with other mycobacterial species (Grange, 1982). However, even within such closely related groups enough heterogeneity can be demonstrated to be useful for epidemiological purposes.

The amino acid breakdown/utilization test devised by Grange (1976) identified considerable variation between the strains studied here. The exceptions were the three strains of $M$. tuberculosis, which were completely non-reactive with all the amino acids tested. In all the other taxa studied some degree of heterogeneity was observed. This system has previously been used to study the epidemiology of $M$. bovis infection in cattle and badgers and with proper safeguards there seems to be no reason why it should not be used for other taxa.

Barrow (1981) was concerned that the possible risk of fungal and bacterial contamination should be eliminated. The former is relatively easily dealt with since fungal growth is visible to the naked eye. Inclusion of appropriate antibiotics in the saline used for suspending the mycobacterial growth could eliminate both sources of potential contamination. It is essential that a typing system advocated for epidemiological investigations is shown to give reproducible results even if phenotypic or genotypic instability in the bacteria examined introduce variability into the results.

SDS-PAGE can demonstrate variability between bacterial strains by identifying small differences in proteins (Whitney et al., 1968; Rouatt et al., 1970). Numerical taxonomy can be applied to quantitative estimations of these differences (Kersters \& De Ley, 1975) and will eliminate minor sources of variability. However, even without such treatment of the results SDS-PAGE has been shown in the present study to demonstrate easily recognizable differences between strains of $M$. bovis.

The choice of a typing system for any bacterial species depends on the simplicity and ease of use of the method coupled with the reproducibility of the results in addition to the ability to identify several useful sub-specific groups. With such criteria, none of the systems described here are ideal. Thus, further study and a rigorous assessment of the systems described is advocated.

Thanks are due to Dr J. Grant and Dr D. Broadbent, London School of Hygiene and Tropical Medicine, and Dr J. Grange, Public Health Laboratory, Dulwich Hospital. The author was supported by a post-doctoral Research Fellowship from the Nature Conservancy Council.

\section{REFERENCES}

BARRow, P. A. (1981). Aspects of the epidemiology of bovine tuberculosis in badgers and cattle. II. The development and use of a typing system for Mycobacterium bovis. Journal of Hygiene 86, 247257.

Barrow, P. A. \& Gallagher, J. (1981). Aspects of the epidemiology of bovine tuberculosis in badgers and cattle. I. The prevalence of infection in two wild animal populations in south-west England. Journal of Hygiene 86, 237-245.

Bates, J. H. \& Mitchison, D. A. (1969). Geographic distribution of bacteriophage types of Mycobacterium tuberculosis. American Review of Respiratory Diseases 100, 189-193.

Collins, C. H., Yates, M. D. \& Grange, J. M. (1982). Subdivision of Mycobacterium tuberculosis for epidemiological purposes: methods and nomenclature. Journal of Hygiene 89, 235-242.

GraNGE, J. M. (1976). Enzymic breakdown of amino acids and related compounds by suspensions of washed mycobacteria. Jaurnal of Applied Bacteriology 41, 425-431.
Grange, J. M. (1982). Koch's tubercle bacillus - a centenary reappraisal. Zentralblatt für Bakteriologie und Hygiene, I. Abt., Orig. A 251, 297-307.

KERSTERS K. \& DE LEY, J. (1975). Identification and grouping of bacteria by numerical analysis of their electrophoretic protein patterns. Journal of General Microbiology 87, 333-352.

Rouatt, J. W., Skyring, G. W., Purkayastha, V. \& QuAdling, C. (1970). Soil bacteria: numerical analysis of electrophoretic protein patterns developed in acrylamide gels. Canadian Journal of Microbiology 16, 202-205.

Whitney, P. J., Vaughan, J. G. \& Heale, J. B. (1968). A disc electrophoretic study of the proteins of Verticillium albo-atrum, Verticillium dahliae and $\mathrm{Fu}$ sarium oxysporum with reference to their taxonomy. Journal of Experimental Botany 19, 415-426.

Wieten, G., Haverkamp, J., Meuzelaar, H. L. C., ENGel, H. W. B. \& Berwald, L. G. (1981). Pyrolysis mass spectrometry: a new method to differentiate between the mycobacteria of the 'tuberculosis complex' and other mycobacteria. Journal of General Microbiology 122, 109-118. 